\title{
Evaluation of pelvic organ prolapse by standardized POP Q system for vaginal hysterectomy
}

\author{
Vandana Dhama*, Rachna Chaudhary, Shakun Singh, Manisha Singh
}

Department of Obstetrics and Gynecology, IIRM Medical College, Meerut, Uttar Pradesh, India

Received: 13 April 2017

Accepted: 08 May 2017

\section{*Correspondence:}

Dr. Vandana Dhama,

E-mail: vandanallrm@yahoo.com

Copyright: (c) the author(s), publisher and licensee Medip Academy. This is an open-access article distributed under the terms of the Creative Commons Attribution Non-Commercial License, which permits unrestricted non-commercial use, distribution, and reproduction in any medium, provided the original work is properly cited.

\begin{abstract}
Background: Uterovaginal prolapse is a common condition affecting women in reproductive and perimenopausal age groups. Evaluating pelvic organ prolapse in an objective, reproducible, easy to apply method is required for proper management. Aim of the study was preoperative and postoperative evaluation of pelvic organ prolapse by POP Q system in patients undergoing vaginal hysterectomy.

Methods: In this observational study, 100 patients having pelvic organ prolapse, (average age $48 \pm 12$ years), underwent elective vaginal hysterectomy at Lala Lajpat Rai Memorial Medical College Meerut during June 2015 to July 2016. POP Q was done preoperatively and after completion of surgery by the same surgeon.

Results: The mean of genital hiatus preoperatively was 6.4 and post operatively it was 3.64 i.e. the genital hiatus was reduced by 2.76 . The mean of total vaginal length pre-operatively was 8.07 and post operatively was 7.2. There was only $0.9 \mathrm{~cm}$ reduction in the vaginal length. The mean of perineal body pre-operatively was 2.64 and post operatively was 3.64. The points preoperatively were Aa 2.35, Ba 2.61, C 2.57, Ap 2.24, Bp 0.96, D-4.79 and post-operative the value of the points was $-2.19,-2.04,-5.57,-2.98,-2.52$ respectively and D point absent due to hysterectomy.

Conclusions: The post-operative POP Q was analysed and the patients having grade 0 were 63 (optimum anatomical outcome) and patients having grade 1 were 36 (satisfactory anatomical outcome).
\end{abstract}

Keywords: Pelvic organ prolapse, POP Q, Vaginal hysterectomy

\section{INTRODUCTION}

Pelvic Organ Prolapse is defined as a downward or forward displacement of pelvic organ from its normal location.

Pelvic organ prolapse occurs when there is a weakness in the supporting structures of pelvic floor allowing the pelvic viscera to descend. Symptoms associated with prolapse are often difficult to correlate with the anatomical site or severity of the 'bulge' and are often nonspecific. ${ }^{1}$ Women with prolapse typically complain of something coming out of vagina or the sensation of vaginal 'heaviness', recurrent irritative bladder symptoms, voiding difficulty, incontinence or defecatory difficulty.
Surgery for pelvic organ prolapse accounts for approximately $20 \%$ of elective major gynecological surgery and this increases to $59 \%$ in elderly women. The lifetime risk of requiring surgery for prolapse is $11 \% .^{2}$

Approximately half of all women over the age of 50 years complain of symptomatic prolapse. ${ }^{3}$ The commonly used methods of classifying and grading genital prolapse are subjective with high interobserver variations. This absence of standardization means there is difficulty in comparing surgical results of different doctors.

In 1996, Bump et al presented a standard system of terminology for the description of female pelvic organ prolapse and pelvic floor dysfunction. ${ }^{4}$ It was an 
objective site-specific system for describing, quantifying, and staging pelvic organ prolapse.

In POP Q, fixed reference point used for measurement is hymenal ring. Specific measurements at nine sites are recorded in a tic-tac-toe grid so interobserver agreement is good. [5]. It has been shown that the routine use of the POP-Q system decreases significantly the amount of time needed to collect the desired data. ${ }^{6}$

\section{METHODS}

This observational prospective study on 100 patients was conducted in the Department of Obstetrics and Gynaecology, L.L.R.M. Medical College, S.V.B.P. Hospital Meerut from July 2015 to September 2016.

\section{Inclusion criteria}

- Patients complaining of something coming out of vagina

- $\quad$ Between the age of 35- 60 years.

- $\quad$ BMI between 18.5- 27

\section{Exclusion criteria}

- Pregnancy or 6 weeks peurperium,

- Any major cardiovascular, respiratory, neurological, abdominal illness.

- Stress urinary incontinence, urge incontinence (sensory or motor), Vault prolapse.

Patients included in study group were examined in OPD to assess their POP-Q score. The surgeon asked direct question about sign and symptoms of pelvic organ prolapse in the language of the patient. Informed consent was taken for the physical examination.

Examination for pelvic organ prolapse was done in dorsal lithotomy position (position in which the patient is on their back with the hips and knees flexed and thighs apart) in OPD. Inspection of the vulva and perineum was done first.

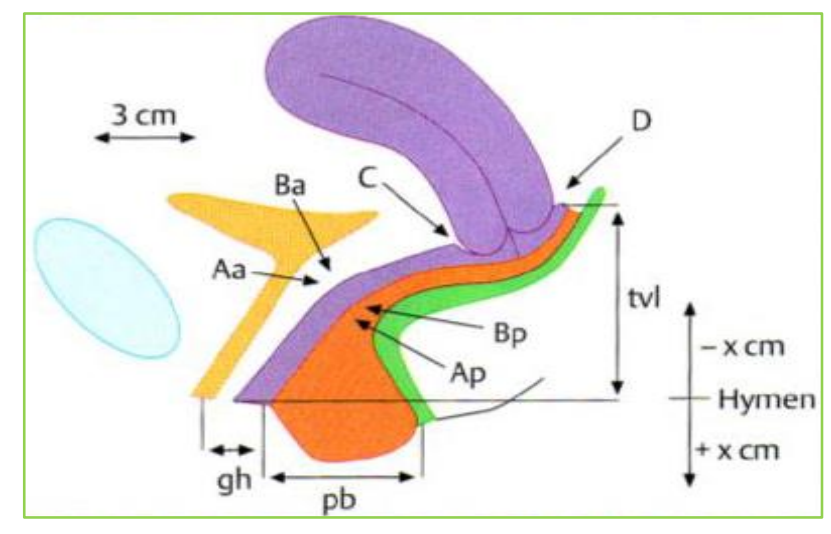

Figure 1: Illustration of points of POP Q.
After inspection, the labia were separated and any prolapse was noted. Prolapse was graded by using the POP Q system. Plane of hymen is defined as zero. Points above hymen were given negative number and points below hymen positive number (Figure 1). All the measurements were made in $\mathrm{cm}( \pm 0.5 \mathrm{~cm})$.

\section{$P O P Q$ system has following points of measurement}

- Aa: It is a fixed landmark. It defines a point that lies in the midline of the anterior vaginal wall and is 3 $\mathrm{cm}$ proximal to the external urethral meatus. It corresponds to the proximal location of the urethrovesical crease. In relation to the hymen, this point ranges from -3 (i.e. normal support) to +3 (i.e. maximum prolapse)

- $\quad \mathrm{Ba}$ : It is a variable point and refers to the most distal position of any part of the remaining upper anterior vaginal wall. It is $-3 \mathrm{~cm}$ in the absence of prolapse. Points range is -3 (in the absence of prolapse) to $+t v l$ $(-3$ to +8$)$. In the absence of prolapse $\mathrm{Aa}$ and $\mathrm{Ba}$ are almost same point i.e. (-3).

- Ap: It defines a point that lies in the midline of the posterior vaginal wall and is $3 \mathrm{~cm}$ proximal to the hymen. This point's range is -3 (i.e. normal support) to +3 (maximum prolapse of point Ap).

- $\mathrm{Bp}$ : it is also a variable point, most distal point of the remaining upper posterior vaginal wall. Point range is -3 (in the absence of prolapse) to $+\operatorname{tvl}(-3$ to +8$)$

- In the absence of prolapse Ap and Bp are almost the same point $(-3)$.

- Total vaginal length (tvl): greatest depth of the vagina in centimeters measurement is taken without straining (normal range is $8-12 \mathrm{~cm}$ ).

- Genital hiatus (gh): middle of external urethral meatus to the posterior midline of hymen (range 2-4 $\mathrm{cm})$.

- $\quad$ Perineal body (pb): posterior margin of genital hiatus to midanal opening (approx. $3 \mathrm{~cm}$ ).

- D (douglas): level of uterosacral ligament attachment to the posterior cervix (no cervix $=$ no $\mathrm{d}$ point, range -8 to -10$)$.

- C (cervix or vaginal cuff): most distal edge of the cervix or leading edge of the vaginal cuff.

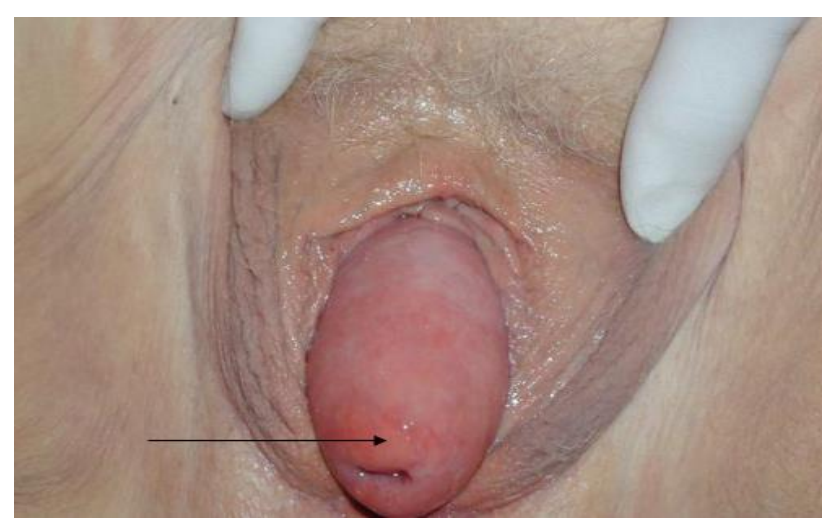

Figure 2: Point C; cervix. 
After asking patient to lie in dorsal lithotomy position (Position in which the patient is on their back with the hips and knees flexed and the thighs apart.) Sims speculum was used to examine prolapse. All the measurements were made by using a marked ayre's spatula.

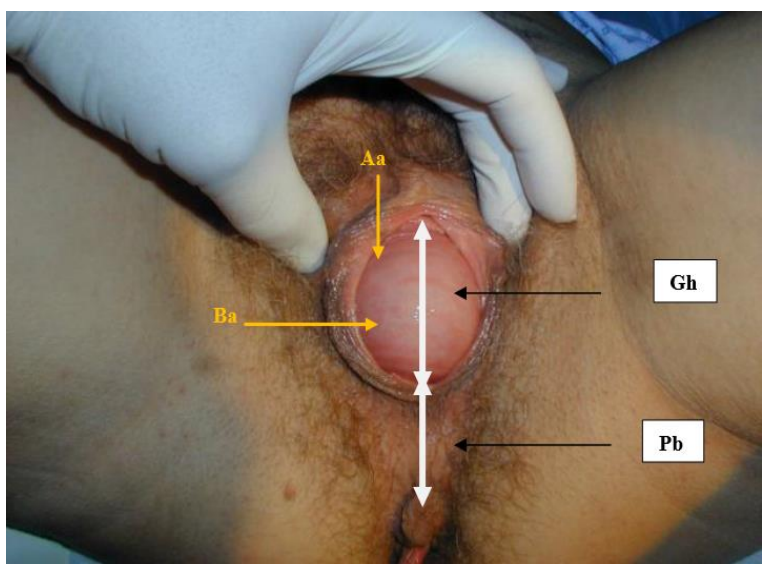

Figure 3: Position of points Aa, Ba genital hiatus and perineal body.

Gh, $\mathrm{Pb}$ (Figure 2) and Tvl were measured first when the prolapse was reduced and patient asked not to strain. Aa and Ap were marked using marker pen. Then patient was asked to strain maximally $\mathrm{C}$ point (Figure 2), Aa, Ba, Ap, Bp points (Figure 3,4 ) were measured and last $\mathrm{D}$ point was measured.Grading of prolapse was decided by the distal edge of prolapse. Graph was made for assessing the measurements in preop and postop examination (Figure $5)$.

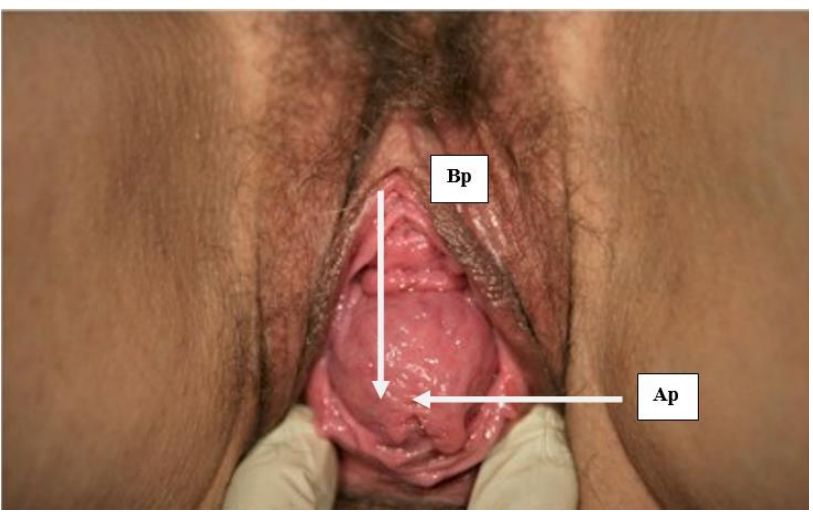

Figure 4: Position of points Ap and Bp.

After completion of vaginal hysterectomy with site specific repair, post-operative POP Q scoring was done by surgeon in dorsal lithotomy position.

Anatomical optimization was assessed on basis of comparison of pre-and postop scores. Same surgeon did the preop scoring, vaginal hystererctomy, post op POP Q scoring. The values were filled in the following tic tac toe grid design for each patient.
Table 1: Tic tac toe grid.

\begin{tabular}{|lll|}
\hline $\begin{array}{l}\text { Aa } \\
\text { Anterior } \\
\text { vaginal wall }\end{array}$ & $\begin{array}{l}\text { Ba } \\
\text { Anterior } \\
\text { vaginal wall }\end{array}$ & $\begin{array}{l}\text { Cervix or } \\
\text { cervical cuff }\end{array}$ \\
\hline $\begin{array}{l}\text { Gh } \\
\text { Genital hiatus }\end{array}$ & $\begin{array}{l}\mathrm{Pb} \\
\text { Perineal body }\end{array}$ & $\begin{array}{l}\text { Tvl } \\
\text { Total vaginal } \\
\text { length }\end{array}$ \\
\hline $\begin{array}{l}\text { Ba } \\
\text { Posterior vaginal } \\
\text { wall }\end{array}$ & $\begin{array}{l}\text { Bp } \\
\text { Posterior } \\
\text { vaginal wall }\end{array}$ & $\begin{array}{l}\text { Posterior } \\
\text { fornix }\end{array}$ \\
\hline
\end{tabular}

\section{RESULTS}

Mean age of patients was 47 years (Table 3). The distribution of patients according to POP Q classification was $16 \%$ in grade $2,49 \%$ in grade 3 and $35 \%$ in grade 4 (Table 4).

Table 2: Staging of prolapse.

\begin{tabular}{|ll|}
\hline Stage 0 & $\begin{array}{l}\text { No Prolpase } \\
\text { Points Aa, Ba, Ap, Bp are all at }-3 \mathrm{~cm} .\end{array}$ \\
Stage I & $\begin{array}{l}\text { The most distal portion of the prolapse is } \\
\text { more than } 1 \mathrm{~cm} \text { above the level of hymen } \\
\text { Quantification value is less than }-1 \mathrm{~cm} .\end{array}$ \\
Stage II & $\begin{array}{l}\text { The most distal portion of the prolapse is } 1 \\
\text { cm or less proximal or distal to the hymen } \\
\text { Quantification value is } \geq-1 \mathrm{~cm} \text { but } \leq+1 \mathrm{~cm}\end{array}$ \\
\hline Stage III & $\begin{array}{l}\text { The most distal portion of the prolapse } \\
\text { protrudes more than } 1 \mathrm{~cm} \text { below the } \\
\text { hymenal plane. Quantification value is }>+1 \\
\text { but <+(tvl -2cm) }\end{array}$ \\
\hline Stage IV & $\begin{array}{l}\text { Complete eversion of vaginal walls. } \\
\text { Quantification value }>(+T \mathrm{~T} l-2 \mathrm{~cm})\end{array}$ \\
\hline
\end{tabular}

Table 3: Distribution of patients according to age.

\begin{tabular}{|lll|}
\hline Age group in years & No. of patients $(n=100)$ & $\%$ \\
\hline $35-40$ & 2 & 2 \\
\hline $40-45$ & 2 & 2 \\
\hline $46-50$ & 44 & 44 \\
\hline $51-55$ & 28 & 28 \\
\hline $56-60$ & 18 & 18 \\
\hline
\end{tabular}

On comparing the pre opearative and post-operative POP $\mathrm{Q}$ of the patient, the reduction in genital hiatus was by $3 \mathrm{~cm}$. The perineal body was increased by $1.5 \mathrm{~cm}$ and there was not much effect on the TVL (total vaginal length) which was reduced by $0.5 \mathrm{~cm}$, from a mean Tvl of 8.7 to 8.2 . The reduction in point $\mathrm{Aa}$ is by $4.5 \mathrm{~cm}$ in $\mathrm{Ba}$ was $4.6 \mathrm{~cm}$ the points were reduced to 2.19 and -2.04 respectively. The point $\mathrm{C}$ was rduced from +2.5 to -5.5 i.e. a reduction of $7 \mathrm{~cm}$. point Ap was reduced by $0.74 \mathrm{~cm}$ and $\mathrm{Bp}$ was reduced by $2.55 \mathrm{~cm}$. The points Ap and Bp were reduced to approximately -3 position, which is our normal anatomical position of the points Ap and Bp (Table 5). Mean parity was 5 (Table 6). 
Table 4: Distribution of patients according to staging of prolapse.

\begin{tabular}{lll} 
Pop Q stage & No. of patients $(n=100)$ & $\%$ \\
Stage 1 & 0 & 0 \\
\hline Stage 2 & 16 & 16 \\
Stage 3 & 49 & 49 \\
\hline Stage 4 & 35 & 35 \\
\hline
\end{tabular}

Table 5: Preoperative and postoperative mean of the points used to grade prolapse.

\begin{tabular}{|lll|}
\hline Refrence point & Pre OP (mean) & Post OP (mean) \\
\hline $\mathrm{Aa}$ & 2.35 & -2.19 \\
\hline $\mathrm{Ba}$ & 2.61 & -2.04 \\
\hline $\mathrm{C}$ & 2.57 & -5.57 \\
$\mathrm{Ap}$ & -2.24 & -2.98 \\
\hline $\mathrm{Bp}$ & 0.96 & -2.52 \\
\hline $\mathrm{D}$ & -4.79 & \\
$\mathrm{GH}$ & 6.4 & 3.39 \\
\hline $\mathrm{PB}$ & 2.64 & 4.14 \\
\hline TVL & 8.7 & 8.2 \\
\hline
\end{tabular}

Table 6: Patients distribution according to parity.

\begin{tabular}{|lll|}
\hline Parity & No. of patients $(\mathrm{n}=\mathbf{1 0 0})$ & $\%$ \\
\hline Upto2 & 7 & 7 \\
\hline $3-5$ & 58 & 58 \\
\hline $6-8$ & 26 & 26 \\
\hline$>8$ & 9 & 9 \\
\hline Total & 100 & 100 \\
\hline
\end{tabular}

\section{DISCUSSION}

The standard POP Q system has a long learning curve as some experience is required to exactly interpret the anatomical points. The authors used POPQ classification by American Urogynaecologic society and did POP Q assessment on 20 patients in OPD before undertaking the study.

In our study, according to POP Q classification $16 \%$ had grade 2 prolapse, $49 \%$ had grade 3 prolapse and $35 \%$ had grade 4 prolapse. In a study by Seo JT et al the overall distribution of POP Q stage was stages 0 to 4 in $68.3 \%$, $19.9 \%, 11.2 \%, 0.6 \%$ and $0.0 \%$ of patients. ${ }^{7}$

In a study by Yuvaraj TP et al the average preoperative scoring was $(\mathrm{Aa}+1.7, \mathrm{~B}+3.5, \mathrm{C}+4, \mathrm{GH} 5.1, \mathrm{~PB} 2$, TVL 8.9, $\mathrm{Ap}+0.5, \mathrm{Bp}+2.2, \mathrm{D}+4.1)$. The average postoperative scoring was (Aa-2.94, B -3.2, C-6, GH 3.1, PB 4.2, TVL 6.9, Ap -2.9, Bp -3.2, D-6). ${ }^{8}$ In the present study, something coming out of vagina was the most consistent symptom found in $84 \%$ patients which was comparable to the study conducted by $\mathrm{O} \mathrm{P}$ Awotunde et al in which it was $96 \% .^{9}$ The definition of optimal anatomic outcome was POP-Q stage 0 and satisfactory anatomic outcome was stage 1 (Table 2). For the evaluation of postoperative success of surgery, the post-operative POP Q was analysed and 63 out of 100 patients had optimum anatomical outcome and 36 patients had satisfactory anatomical outcome and 1 had unsatisfactory anatomical outcome. After analysis, it was observed that when vault suspension was done, anatomical outcome was better.

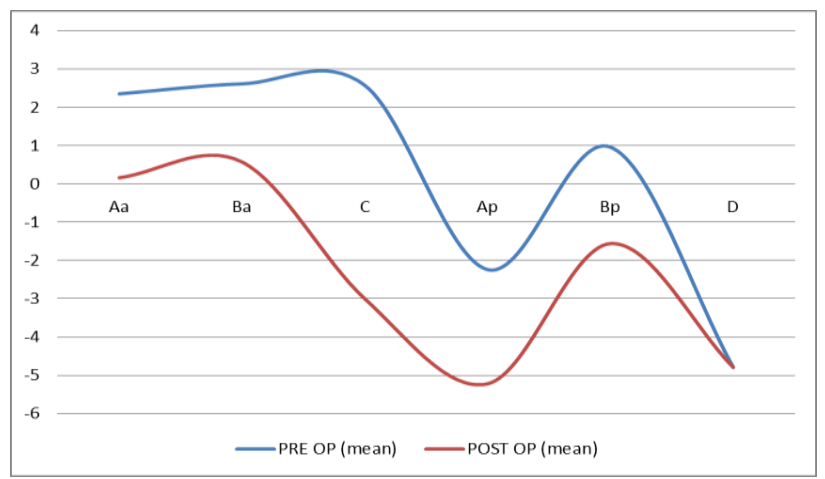

Figure 5: Pre-operative and post-operative POP Q evaluation.

Standardization Subcommittee of the International Continence Society created the Pelvic Organ Prolapse Quantification (POP-Q) system in 1996. ${ }^{10,11}$ Although initially it may take more time to record data in grid but with repeated use of the POP-Q system the time decreases. ${ }^{12}$ Another advantage of POP Q assessment is good reproducibility when different doctors do the assessment. This makes it easy to compare the results of different clinical studies. However, POP Q system also does not identify unilateral or asymmetrical defects.

The system relies on specific measurements of defined points in the midline of the vaginal wall. The fixed reference point used for measurement is hymenal ring (zero point). Surgeon can evaluate anatomical correction of prolapse immediately after hysterectomy and compare with preoperative score. As shown in our study, anatomical correction after vaginal hysterectomy can be evaluated in an objective manner. Different surgeons can compare their results for anatomical correction.

Limitations of present study were a small sample size, different operating surgeons and no standardized operating technique for all patients. Also, the patients were not followed up for assessing link between anatomical correction and functional improvement in prolapse symptoms.

Funding: No funding sources

Conflict of interest: None declared

Ethical approval: Not required

\section{REFERENCES}

1. Swift SE, Tae SB. Correlation of symptoms with degree of pelvic organ support in a general population of women: What is pelvic organ prolapse? Am J Obstet Gynecol. 2003;189:372-9. 
2. Olsen AL, Smith VG, Bergstrom JO, Colling JC, Clark AL. Epidemiology of surgically managed pelvic organ prolapse and urinary incontinence. Obstet Gynecol. 1997;89:501-6.

3. Swift SE. The distribution of pelvic organ support in a population of female subjects seen for routine gynecologic health care. Am J Obstet Gynecol. 2000;183:277-85.

4. Bump RC, Mattiasson A, Bo K, Brubaker LP. The standardization of terminology of female pelvic organ prolapse and pelvic floor dysfunction. Am J Obstet Gynecol. 1996;175(1):10-17.

5. Swift S. Validation of a simplified technique for using the POPQ pelvic organ prolapse classification system . Int Urogynecol J. 2006;17:615-20.

6. Hoffman B, Schorge J, Schaffer J. Pelvic organ prolapse, Williams gynaecology $2^{\text {nd }}$ ed. 2012;644.

7. Seo JT, Kim JM. Pelvic organ support and prevalence by Pelvic Organ Prolapse-Quantification (POP-Q) in Korean women. J Urol. 2006;175(5):1769-72.

8. Yuvaraj TP, Mahale AR. Assessment of prolapse by Pelvic Organ Prolapse Quantification (POP Q) System. Indian J Basic Appl Med Res. 2014;3:32430 .

9. Awotunde OT, Fehintola AO, Ogunlaja OA, Olujide LO, Aaron OI, Bakare $\mathrm{B}$ et al. An audit of uterovaginal prolapse in Ogbomoso, south-west Nigeria. Res J Health Sci. 2016;4(1):31-6.

10. Abrams P, Cardozo L. The standardisation of terminology of lower urinary tract function: Report from the Standardisation Subcomitee of International Continence Society. Am J Obstret Gynecol. 2002;187:116-26.

11. Bump RC. The standardization of terminology of female pelvic organ prolapse and pelvic floor dysfunction . Am J Obstret Gynecol. 1996;175:10-7.

12. Hall AF, Theofrastous JP, Cundiff GW, Harris RL, Hamilton LF, Swift SE et al. Interobserver and intraobserver reliability of the proposed International Continence Society, Society of Gynecologic Surgeons, and American Urogynecologic Society pelvic organ prolapse classification system. Am J Obstet Gynecol. 1996;175(6):1467-70.

Cite this article as: Dhama V, Chaudhary R, Singh S, Singh M. Evaluation of pelvic organ prolapse by standardized pop q system for vaginal hysterectomy. Int J Reprod Contracept Obstet Gynecol 2017;6:2584-8. 